\title{
The Role of Prosodic Reading in English Reading Comprehension among Cantonese-English Bilingual Children
}

\author{
Rachel Ka-Ying Tsui, Xiuli Tong, Leo Shing-Chun Fung \\ Division of Speech and Hearing Sciences, The University of Hong Kong, Hong Kong \\ rachelkt@hku.hk, xltong@hku.hk, leofung@hku.hk
}

\begin{abstract}
We examine the role of prosodic reading in English reading comprehension among Cantonese-English bilingual children by characterizing the acoustic characteristics of bilingual children's English prosodic production and relating them to their English reading comprehension. Spectrographic analysis was performed on six types of syntactically complex structures from an English passage orally produced by the participants, with a focus on pitch pattern and pause structure. Pitch patterns produced by our bilingual children were found to show similar patterns to those produced by Englishspeaking adults as reported in previous studies. However, pause structures produced by the bilingual children were different from the native English speakers. Furthermore, only pitch pattern was significantly associated with English reading comprehension. These results suggest that pitch pattern is a critical factor in determining English reading comprehension among Cantonese-English bilingual children. We discuss these findings in terms of automaticity theory in second language reading acquisition.
\end{abstract}

Index Terms: L2 prosodic reading, Cantonese-English bilingual children, L2 reading comprehension ability

\section{Introduction}

The importance of achieving oral reading fluency in reading skill development has gained a renewed interest. This is largely due to the recognition of a close link between reading fluency and comprehension skill [1, 2, 3], and overall academic achievement as well.

In Hong Kong, children are expected to become proficient readers for both Chinese and English. However, this is challenging due to the complexity of reading comprehension itself, and also the structural differences between Chinese and English in terms of orthography and prosody [4]. As studies have suggested an important role of prosody in reading comprehension (e.g., [5, 6]), this study aims to address the role of English prosodic reading in English reading comprehension among Cantonese-English bilingual children.

\subsection{Prosody in reading}

Prosody is a combination of different acoustic features namely (1) duration, (2) pitch $\left(\mathrm{f}_{0}\right)$, (3) loudness, and (4) pausal intrusion [7]. As prosody could be localized within a single word or across an utterance, it is suprasegmental [8]. The ability to detect the regularity of these features within the rhythmic patterns of language marks prosodic sensitivity [8], which is closely related to reading. There are at least six identified distinctive speech indicators associated with prosodic reading: (a) phrase-final lengthening, (b) pausal intrusion, (c) terminal intonation contour, (d) appropriateness of phrases, (e) stress, and (f) length of phrases [9]. Reader's ability of applying syntactic knowledge to text during reading is reflected by appropriate use of the above markers to segment text according to major syntactic and semantic elements while preserving speed and accuracy [5]. Proper use of prosody therefore serves as a reflection of appropriate parsing of text into comprehensible units [10].

Prosody plays a role in reading comprehension [5]. According to implicit prosody hypothesis, a default prosodic contour is unconsciously superimposed onto text during silent reading, and it may facilitate syntactic ambiguity resolution [11]. Such hypothesis was supported by eye-movement studies that readers obtain prosodic information in both silent and oral reading situations (e.g., [12]). Normal developing children trying to acquire and master spoken language and written text comprehension are indirectly aided by their sensitivity to prosodic information [13]. There is an underlying notion that the achievement of reading fluency could be signaled by the occurrence of prosodic reading $[9,14,15]$.

The function of punctuation ties closely with syntax and is important to signal appropriate prosodic reading. For example, grammar rules governing phrase-final comma placement between words may dictate pauses in sentences such as "She came, she schmoozed, and she dazzled" but not in those like "Peter wanted the one with the white, blue, and red sprinkles" [16]. There is also prosodic uncertainty regarding question marks, as yes-no questions end with a final pitch rise (e.g., "Did Mary go?") but not wh questions (e.g., "Where did Mary go?") [5]. Readers might have difficulties in parsing a sentence if boundary pitch pattern is elicited wrongly by the punctuation mark [5]. Successful prosodic reading requires awareness of the limitation of punctuation as prosodic features need to be abstracted by readers during reading aloud [5].

Previous studies with English monolingual readers have established the important link between prosodic reading and reading comprehension. Miller and Schwanenflugel [5] found that pitch variations make independent contribution to reading comprehension: children who demonstrated greater pitch fall (rise) at declarative sentences (yes-no questions) tended to have better reading comprehension skills. Also, a longitudinal study found that acquisition of adult-like intonation and decrease in the number of pausal intrusions between $1^{\text {st }}$ and $2^{\text {nd }}$ grades contributed to better reading comprehension at $3^{\text {rd }}$ grade [6]. Well-developed prosodic reading is therefore associated with better reading comprehension $[5,6]$.

\subsection{Universal features of prosody}

Prosody is a universal linguistic subsystem serving as many functions in all languages [13]. One universal property of prosody is the interface between syntactic and prosodic breaks 
[17]. At phrasal level, parsing decisions are reliably informed by prosodic boundaries [10]. It also reduces listeners memory load by helping to hold an utterance until more complex and abstract semantic and syntactic processes occur [18].

Another universal property of prosody is that intonation indicates semantic, grammatical, and pragmatic functions in speech organization $[19,20]$. For sentence final positions, commands, neutral statements, or neutral questions, there is a strong universal tendency to be marked with falling tones [21]. Sentence non-final phrases, tentative/implication statements, requests, or sympathetic questions are usually marked with rising tones [21].

Most studies on prosodic reading and reading comprehension have largely focused on the context of L1 (e.g., [22, 23, 24]). However, there are few studies which have focused on the case of L2. Most studies on L2 reading comprehension focused on reading fluency (i.e., speed and accuracy) rather than prosodic reading (e.g., [25]). As prosody could be structurally different across different languages [26], studies on L2 prosodic reading may shed light on universal properties of prosody and its role in L2 reading comprehension. Thus, the present study explores CantoneseEnglish children's L2 (i.e. English) prosodic reading skill and its relation with reading comprehension.

\subsection{Prosodic difference in Cantonese and English}

There are language-specific differences in prosody across languages, such as Cantonese and English. Cantonese is a tonal language in which prosody functions as a primary cue to distinguish meaning at the lexical level [27]; therefore intonation and tone are realized simultaneously through prosody [28]. Compared to non-tonal languages, intonation in Cantonese is perceived to be limited since intonation and tone compete for the same phonological and phonetic space [28]. On the other hand, in a stress language like English, intonation relevant to semantic requirement of utterances is conveyed by sentence stress located on word units [29]. In other words, English uses prosody at a higher (phrase, clause, and discourse) level to a much greater extent than does Cantonese [30]. Due to the limited space reserved for intonation in Cantonese, Cantonese also relies on the use of final sentence particles to function as pragmatic markers [30]. These particles contribute to sentence meaning in a way similar to how prosody signals intonation in English [30].

Given the differences in prosody between Cantonese and English, it is theoretically important to explore how Cantonese tone speakers who are English L2 learners produce English prosodic features when reading English passages. Studying Cantonese-English bilingual children provides unique insight into the impact of the role of L2 prosody in L2 reading comprehension. Thus, there are two research questions addressed in this study: (1) What are the acoustic features that characterize oral reading of English passages in CantoneseEnglish bilingual children? (2) Is there any relationship between L2 prosodic reading and L2 reading comprehension among Cantonese-English bilingual children?

\section{Method}

\subsection{Participants}

A group of thirty-six $2^{\text {nd }}$ grade Cantonese-English bilingual children (10 boys; mean age $=7$ years 11 months, $S D=3.45$ months) were recruited. Grade 2 children were chosen because, according to Stage of Reading Development [31], they are expected to have achieved automaticity and eventually prosodic text reading skills. Inclusive criteria include: (a) first language was Cantonese and received English language education for at least 2 years; (b) typically developing without any language delay and learning disability.

\subsection{Reading prosody assessments and procedures}

An English passage was created to measure children's English reading prosody. Since decoding errors would lead to meaningless determination of reading prosody, the passage was generated through careful selection of words according to Wordlists for the Primary English Language Curriculum [32]. The passage was 99 words long and consisted of 12 sentences. We targeted at six different types of structure, each occurring twice in the passage: (1) basic declaratives, (2) basic quotatives, (3) yes-no questions, (4) wh questions, (5) complex adjectival comma phrases, and (6) phrase-final commas between two clauses.

Children were instructed to read the passage aloud as expressive as and as well as they could; an example recording of expressive reading of another English short story was played as demonstration. The recording session took place in a quiet room. Children's oral reading production was recorded (with a sampling rate of $44.1 \mathrm{kHz}$ ) via an Edirol USB Audio Capture UA-25, a Lenovo ThinkPad E450 Laptop, and a AKG SE300 B microphone pre-amplifier with CK91 cardioid condenser microphone capsule. Praat [33] was used to create individual digital .wav file for each participant.

When recording was done, five short-answer questions regarding the English read-aloud passage were asked to ensure the participants comprehended the passage while reading. These five questions were not adequate to assess children's reading comprehension ability. A standardized reading comprehension task was included in the later analyses instead.

\subsection{General reading assessments and procedures}

\subsubsection{Word reading efficiency assessment}

The Test of Word Reading Efficiency (2 ${ }^{\text {nd }}$ Edition) Form A [34] was administered to test children's word reading skill. Children were presented with lists of (1) sight word efficiency and (2) phonemic decoding efficiency: they were given 45 seconds for each list to read as many words as possible.

\subsubsection{Oral reading fluency assessment}

Children's connected text reading fluency was measured by calculating the number of word correct per minute (WCPM) in the production of the English passage administered for prosody measurement.

\subsubsection{Reading comprehension assessment}

Grade 1 and Grade 2 Comprehension subtest of the GatesMacGinitie Reading Test, $4^{\text {th }}$ Edition [35] were administered. In each level, there were 39 multiple-choice questions. Children were required to select a picture that best represented the sentence for each question.

\subsubsection{Nonverbal intelligence}

Nonverbal intelligence was measured with the subtest of matrix reasoning adopted from Wechsler Abbreviated Scale of Intelligence, $2^{\text {nd }}$ Edition [36]. Children were presented with an 
incomplete matrix and required to select the correct option that could complete the matrix.

\section{Results}

\subsection{Acoustic analyses of English prosodic production by Cantonese-English bilingual children}

To explore the acoustic characteristics that characterize Cantonese-English bilingual children's English prosodic production, acoustic analysis of recordings obtained from each participant was conducted using Praat [33]. The following six linguistic features were targeted for spectrographic measurement with reference to features found in Englishspeaking adults' prosodic reading [5, 15, 37]: (1) basic declarative sentences (elicit pitch decline at the end of the sentence); (2) basic quotatives (elicit short pause following quote); (3) wh questions (may not elicit uprising pitch); (4) yes-no questions (elicit pitch rise); (5) complex adjectival phrase commas (may not elicit pauses); (6) phrase-final commas (may elicit pauses following phrase) (see Figure 1). Pause lengths and $f_{0}$ measurements were collected for each type of structure in the read-aloud passage.

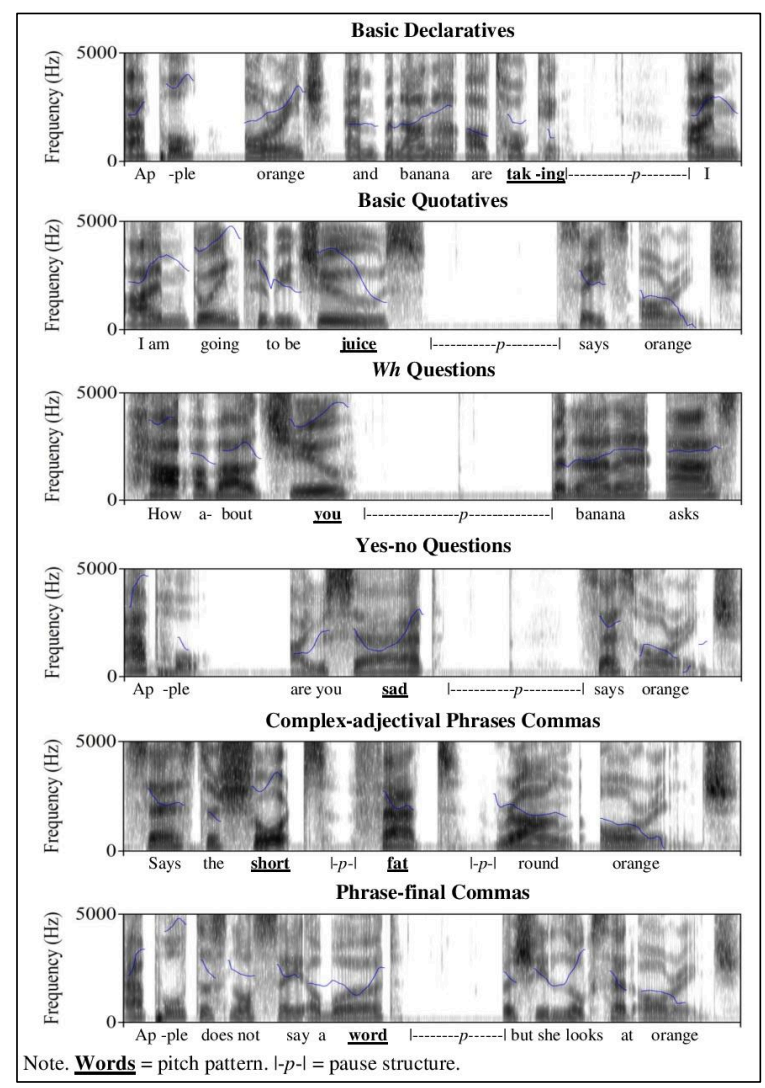

Figure 1: An example of the six targeted structures.

\subsubsection{Pitch measurements}

Fundamental frequency (f0) parameters, i.e., f0 onset, f0 offset, maximum f0, and minimum f0, were obtained. F0 onset and $\mathrm{f0}$ offset were used to determine the direction of pitch contour (pitch falls when f0 onset is greater than f0 offset). Maximum f0 and minimum f0 defined the value of pitch contour (max f0 minus min f0). These f0 parameters were obtained for each type of structure. For basic declaratives, the values were obtained at the sentence-final word. For wh questions, yes-no questions, and basic quotatives, the sentence-final pitch values were measured for the pretag. For phrase-final commas and complex adjectival phrases, pitch values were calculated before the comma. Pitch values were averaged across the two occurrences for each type of sentence.

\subsubsection{Pause length measurements}

The basic declarative pause lengths (in milliseconds) were determined by demarking the spectrograph visually at the limits of sentence-final pauses. Only pause durations between 100 and 3,000 milliseconds were included as required by the Gray Oral Reading Tests protocol [38]. Pause lengths for yesno questions, wh questions, and basic quotatives were extracted through similar procedures. Pause intervals were selected between the sentence-final word in the quote and the beginning of the tag. For complex adjectival phrases and phrase-final commas, pause duration was measured for each comma; the selection of pause length was from the end of the word preceding the comma to the next word following it. The mean pause length was calculated by averaging across the two occurrences for each type of sentence.

\subsubsection{Statistical analyses of prosody features}

A one-way repeated-measures ANOVA was carried out and found a significant main effect of pitch values, $F(5,31)=$ 25.15, $p<.001, \eta_{p}^{2}=.80$. Pairwise comparisons with Bonferroni correction suggested that the rising pitch contour of yes-no question $(M=49.82 \mathrm{~Hz})$ was statistically different from all other five types of sentences that bore falling pitch contour $(p s<.001)$. The falling pitch of complex adjectival phrase $(M=-21.13 \mathrm{~Hz})$ was also significantly different from the other types of sentences ( $p s<.01)$ except that of phrasefinal comma $(M=-44.22 \mathrm{~Hz})(p=1.000)$, suggesting that the pitch fall in complex adjectival phrase and phrase-final comma was not as great as in the other types of sentences. However, the falling pitch of declarative $(M=-126.75 \mathrm{~Hz}), w h$ question $(M=-106.01 \mathrm{~Hz})$, and quotative $(M=-115.53 \mathrm{~Hz})$ were not significantly different from one another $(p s=1.000)$.

Another one-way repeated-measures ANOVA was performed and found a significant effect of pause duration, $F(5,31)=20.92, p<.001, \eta_{\mathrm{p}}^{2}=.77$. Pairwise comparisons with Bonferroni correction showed that the pause duration of complex adjectival phrase $(M=284.97 \mathrm{~ms})$ was significantly shorter than the other five types of sentences $(p s<.01)$. The pause durations of declarative $(M=860.73 \mathrm{~ms})$ and phrasefinal comma $(M=756.33)$ were indistinguishable from one another $(p=1.000)$, but were both significantly longer than that for wh question $(M=517.54 \mathrm{~ms})$ and quotative $(M=$ $467.81 \mathrm{~ms})(p s<.05)$. The difference in pause durations of yes-no question $(M=642.15 \mathrm{~ms})$, wh question, and quotative clause were not statistically significant $(p s>.05)$.

\subsection{English prosody and reading comprehension}

Statistical analysis was carried out to determine the role of English syntactically complex prosody in English reading comprehension within Cantonese-English bilingual children. Correlation coefficients among variables were computed. Significant correlations between Cantonese-English bilingual children's English prosodic production and their English reading comprehension were found. To be specific, there were moderate to strong positive correlations between English 
reading comprehension and (1) English yes-no question pitch change, $r=.44, p<.01$, and (2) English phrase-final comma pitch change, $r=.57, p<.001$. A strong negative correlation was also found between English reading comprehension and English $w h$ question pitch change, $r=-.54, p<.001$. There were also significant positive correlations between reading comprehension and (1) passage reading fluency, $r=.49, p<$ .01 , and (2) word reading efficiency, $r=.63, p<.001$.

A three-step hierarchical regression with English reading comprehension as the dependent variable was conducted. Nonverbal intelligence was entered as the first step, English reading skill (consisting of English word reading efficiency and passage reading fluency) as the second step, and English pitch factor (consisting of the pitch changes for phrase-final comma, yes-no question, and wh question) as the third step. Pause factor was not entered into the model as no significant correlation was found between any pause structure and English reading comprehension. English pitch factor explained $12.4 \%$ of variance in $2^{\text {nd }}$ grade Cantonese-English bilingual children's English reading comprehension (see Table 1).

Table 1. Hierarchical regression analysis for English reading comprehension $(N=36)$.

\begin{tabular}{|l|c|c|c|}
\hline \multicolumn{1}{|c|}{ Variable and order } & $R^{2}$ & $\Delta R^{2}$ & $\beta$ \\
\hline Step 1: Nonverbal ability & .096 & .096 & .283 \\
Step 2: English Reading Skill & .105 & .009 & .239 \\
Step 3: English Pitch Factor & .229 & $.124^{*}$ & $.381^{*}$ \\
\hline
\end{tabular}

$* \mathrm{p}<.05$

\section{Discussion}

In this study, we systematically assessed prosodic reading via six types of structures, along with a set of reading-related linguistic and cognitive tasks and a reading comprehension task. Cantonese-English bilingual children's English prosodic reading showed the following features: (1) there was pitch rise in yes-no question only but not in wh question; (2) there was great pitch declination in declarative; (3) pause structure was similar between declarative and phrase-final comma. We found that only pitch pattern, but not pause structure, was associated with English reading comprehension of CantoneseEnglish bilingual children. These results suggest the importance of L2 pitch patterns in L2 reading comprehension among Cantonese-English bilingual children.

Cantonese-English bilingual children showed the same prosodic patterns as native English speakers. Specifically, Cantonese-English bilingual children pronounced basic declarative sentences with a significant pitch decline and yesno questions with a large pitch rise. They also did not maintain an upswing in pitch when producing $w h$ questions [5, 15]. These features noticeably conform to the way how native English speakers produce them [5, 15, 37].

The current study provides evidence that appropriate pitch features in reading prosody is correlated with comprehension even in a L2 context. We found that the larger the decline in wh question pitch and the greater the rise in yes-no question pitch, the better the children's English reading comprehension. Our results indicate that pitch factor made independent contribution to reading comprehension beyond nonverbal intelligence and reading skill composited of reading fluency and word reading efficiency among Cantonese-English bilingual children. This result is consistent with previous studies showing that larger declarative sentence pitch declines and larger yes-no question pitch rises demonstrated greater reading comprehension skills in native English children [5].

In contrast, there was no significant association between pause structures and reading comprehension. One of the plausible explanations could be due to the fact that our Cantonese-English bilingual children had similar pause structures for phrase-final commas and at the end of basic declarative sentences. Those children seem to perceive phrasefinal commas functioning similarly as full-stops following basic declarative sentences, and therefore as obligatory signals to maintain a longer pause. This overreliance on punctuation as visual cue for pausing is different from the case of native English speakers: English-speaking adults may not pause at phrase-final commas, and skilled child readers would keep the pause short [5,6]. Our Cantonese-English bilingual children thus hold a concept of pause structure that is different from native English speakers. This caused failure in the correlation of pause structures to English reading comprehension.

In fact, Miller and Schwanenflugel [5] has indicated that pitch changes rather than pause structures contribute better to the association between prosody and reading comprehension. The effect of pause structure is highly dependent on the passage used [5, 15]. This could also be the possible explanation for our finding that our children hold a concept of pause structure that is different from native English speakers. Our Cantonese-English bilingual children probably had difficulty with decoding when reading aloud the English passage. Therefore, appropriate pitch contour is a more reliable prosodic indicator of fluent and automatic reading comprehension [5]. According to Automaticity Theory, full prosodic oral reading is possible once fluent and automatic reading is achieved [39]. Our Cantonese-English children were able to read the passage and uttered the appropriate English intonation. The intonation accompanying prosodic reading may have served to provide children feedback on the major semantic and syntactic units of the text [14]. This would help parsing the text into comprehensible units, as well as providing a cognitive skeleton allowing for better retention of auditory sequence in working memory for more complete semantic analyses. Once such automaticity is achieved, cognitive resources can be used to benefit larger goals, i.e. comprehension [40]. Thus, prosody mediates comprehension. Together, our findings add new evidence to existing research by suggesting that automaticity can be achieved in L2 as appropriate understanding of L2 prosody is maintained to facilitate $\mathrm{L} 2$ reading comprehension.

\section{Conclusions}

The current study extends previous studies by characterizing the L2 prosodic features produced by Cantonese-English bilingual children and showing an association between prosodic reading and reading comprehension in L2 context. Also, we found that the appropriate use of L2 intonation is directly associated with L2 reading comprehension. These findings provide new evidence for the application of automaticity theory to L2 context. Future research may consider how prosodic reading of L1 and L2 interact and how both jointly contribute to reading comprehension.

\section{Acknowledgements}

This research was conducted as part of an ongoing research project supported by the Hong Kong Research Grants Council (RGC) awarded to Dr. Xiuli Tong. 


\section{References}

[1] M. C. Danne, J. R. Campbell, W. S. Grigg, M. J. Goodman, and A. Oranje, Fourth-Grade Studetns Reading Aloud: NAEP 2002 Special Study Of Oral Reading. Washington, DC: Institute of Education Sciences, U.S. Department of Education, 2005.

[2] P. L. Donahue, K. E. Voelkl, J. R. Campbell, and J. Mazzeo, NAEP 1998 Reading Report Card For The Nation. Washington, DC: U.S. Department of Education, 1999.

[3] G. S. Pinnell, J. J. Pikulski, K. K. Wixson, J. R. Campbell, P. B Gough, and A. S. Beatty, Listening To Children Read Aloud. Washington, DC: U.S. Government Printing Office, 1995.

[4] D. August, M. Carlo, C. Dressler, and C. Snow, "The critical role of vocabulary development for English Language Learners," Learning Disabilities Research \& Practice, vol. 20, pp. 50-57, 2005.

[5] J. Miller and P. J. Schwanenflugel, "Prosody of syntactically complex sentences in the oral reading of young children," Journal of Educational Psychology, vol. 98, no. 4, pp. 839-853, 2006.

[6] J. Miller and P. J. Schwanenflugel, "A longitudinal study of the development of reading prosody as a dimension of oral reading fluency in early elementary school children," Reading Research Quarterly, vol. 43, no. 4, pp. 336-354, 2008

[7] P. J. Schwanenflugel, M. R. Westmoreland, and R. G. Benjamin, "Reading fluency skill and the prosodic marking of linguistic focus," Reading and Writing, vol. 28, no. 1, pp. 9-30, 2015.

[8] E. Clin, L. Wade-Woolley, and L. Heggie, "Prosodic sensitivity and morphological awareness in children's reading," Jounral of Experimental Child Psychology, vol. 104, no. 2, pp. 197-213, 2009.

[9] S. L. Dowhower, "Speaking of prosody: Fluency's unattended bedfellow," Theory Into Practice, vol. 30, no. 3, pp. 165-175, 1991.

[10] A. Cutler, D. Dahan, and W. van Donselaar, "Prosody in the comprehension of spoken language: A literature review," Language and Speech, vol. 40, no. 2, pp. 141-201, 1997.

[11] J. D. Fodor, "Psycholinguistics cannot escape prosody," in SPEECH PROSODY $2002-1^{\text {st }}$ International Conference of Speech Prosody, April 11-13, Aix-en-Provence, France, Proceedings, 2002, pp. 83-90.

[12] K. Ashby, "Prosody in skilled silent reading: Evidence from eye movements," Journal of Research in Reading, vol. 29, pp. 318333, 2006.

[13] K. Whalley and J. Hansen, "The role of prosodic sensitivity in children's reading development," Journal of Research in Reading, vol. 29, no. 3, pp. 288-303, 2006.

[14] M. R. Kuhn and S. A. Stahl, "Fluency: A review of developmental and remedial practices," Journal of Educational Psychology, vol. 95, no. 1, pp. 3-21, 2003.

[15] P. J. Schwanenflugel, A. M. Hamilton, M. R. Kuhn, J. M. Wisenbaker, and S. A. Stahl, "Becoming a fluent reader: reading skill and prosodic features in the oral reading of young readers," Journal of Educational Psychology, vol. 96, no. 1, pp. 119-129, 2004.

[16] W. Chafe, "Punctuation and the prosody of written language," Written Communcation, vol. 5, pp. 396-426, 1988.

[17] D. Bolinger, "Intonation across languages," in Universals of Human Language, J. Greenberg, Ed. Stanford, CA: Stanford University Press, 1978, pp. 471-524.

[18] S. R. Speer, R. G. Crowder, and L. Thomas, "Prosodic structure and sentence recognition," Journal of Memory and Language, vol. 32, pp. 336-358, 1993.

[19] M. Kehoe, The Development of Prosody and Prosodic Structure. Hauppauge, NY: Nova Science, 2013.

[20] A. Wennerstrom, The Music of Everyday Speech: Prosody and Discourse Analysis. New York, NY: Oxford University Press, 2001

[21] A. Cruttenden, Intonation. Cambridge: Cambridge University Press, 1997.

[22] National Reading Panel, Teaching children to read: An evidence-based assessment of the scientific research literature on reading and its implications for reading instruction. Washington, DC: U.S. Department of Health and Human Service, 2000

[23] R. G. Benjamin and P. J. Schwanenflugel, "Text complexity and oral reading prosody in young readers," Reading Research Quarterly, vol. 45, no. 4, pp. 388-404, 2010.

[24] J. C. Pinto and A. L. Navas, "Effects of reading fluency stimulation with emphasis on prosody," Journal da Sociedade Brasileira de Fonoaudiologia, vol. 23, no. 1, pp. 21-26, 2011.

[25] E. Geva and Z. Yaghoub-Zadeh, "Reading efficiency in native English-speaking and English-as-a-Second-Language Children: The role of oral proficiency and underlying cognitive-linguistic processes," Scientific Studies of Reading, vol. 10, pp. 31-58, 2006.

[26] M. R. Kuhn, P. J. Schwanenflugel, and E. B. Meisinger, "Aligning theory and assessment of reading fluency: Automaticity, prosody, and definitions of fluency," Reading Research Quarterly, vol. 45, no. 2, pp. 230-251, 2010.

[27] C. W. Law, Tonal Characteristics of Early English-Cantonese Bilinguals. Pokfulam, Hong Kong: The University of Hong Kong, 2006.

[28] A. Fox, K. K. Luke, and O. Nancarrow, "Aspects of intonation in Cantonese," Journal of Chinese Linguistics, vol. 36, no. 2, pp. 321-366, 2008.

[29] S. F. Schmerling, Aspects of English Sentence Stress. Austin, TX: University of Texas Press, 1976

[30] M. C. Pennington and N. C. Ellis, "Cantonese speakers' memory for English sentences with prosodic cues," Modern Language Journal, vol. 84, pp. 372-389, 2000.

[31] J. S. Chall, Stages of reading development (vol. 2). Fort Worth, TX: Harcourt Brace, 1996.

[32] English Language Education Section of the Curriculum Development Institute, Wordlists for the Primary English Language Curriculum. Hong Kong: HKSAR Education Bureau, 2009.

[33] P. Boersma and D. Weenink, Praat: Doing phonetics by computer (version 5.4.22). [Online]. Available from http://www.praat.org/

[34] J. K. Torgesen, R. Wagner, and C. Rashotte, Test of Word Reading Efficiency (2nd ed.). Austin, TX: Pro-Ed, 2012.

[35] W. H. MacGinitie, Gates-MacGinitie reading tests (4th ed.). Itasca, IL: Riverside, 2000

[36] D. Wechsler, Wechsler abbreviated scale of intelligence (2nd ed.). San Antonio, TX: NCS Pearson, 2011.

[37] W. E. Cooper and J. Paccia-Cooper, Syntax and speech. Cambridge, MA: Harvard University Press, 1980.

[38] J. L. Weiderholt and B. R. Bryant, Gray Oral Reading Tests (4th ed.). Austin, TX: Pro-Ed, 2001.

[39] D. LaBerge and S. J. Samuels, "Toward a theory of automatic information processing in reading," Cognitive psychology, vol. 6, no. 2, pp. 293-323, 1974.

[40] P. J. Schwanenflugel, E. B. Meisinger, J. M. Wisenbaker, M. R. Kuhn, G. P. Strauss, and R. D. Morris, "Becoming a fluent and automatic reader in the early elementary school years," Reading Research Quarterly, vol. 41, no. 4, pp. 496-522, 2006. 